\title{
Calibration of Aerial Thermal Infrared Imagery for Walrus Population Assessment
}

\author{
DAVID G. BARBER, ${ }^{1}$ PIERRE R. RICHARD, ${ }^{2} \mathrm{KLAUS} \mathrm{P.} \mathrm{HOCHHEIM}^{3}$ and JACK ORR ${ }^{2}$
}

\author{
(Received 6 June 1990; accepted in revised form 14 November 1990)
}

\begin{abstract}
Concurrent aerial photography and emitted thermal infrared $(10.6 \mu \mathrm{m})$ imagery were acquired over walrus hauled out on sea ice in Foxe Basin, Northwest Territories, Canada. Digital thermal infrared data from a Forward Looking Infrared (FLIR) imager provides a method for estimating walrus numbers, since the objects (walrus groups) are considerably warmer than the background (ocean and sea ice). Coincident photographic counts and thermal infrared pixel counts are regressed by means of a least squares linear regression and an estimate of group size predicted from the number of pixels represented by each group.

The results indicate that analog thermal imagery provides an effective means for obtaining a stratification variable that can subsequently be used in survey design. The FLIR walrus estimation approach is evaluated in the context of replicability, both through the physical mechanics and within a limited range of environmental conditions. Precision of FLIR estimated walrus counts is evaluated relative to the precision of photo counts.

Walrus numbers extracted from the digital thermal imagery at a sample swath of $1778 \mathrm{~m}$ are as precise as those obtained from three independent photo counts at a sample swath of $686 \mathrm{~m}$. In this configuration the FLIR provides a $160 \%$ increase in the sampling (area) fraction. Based on these results, we recommend a stratified approach to estimating walrus abundance using a thermal infrared sensor coupled with visual and photographic censusing techniques. We conclude with recommendations for continued analysis of this infrared censusing technique. Key words: walrus, thermal infrared remote sensing, eastern Canadian Arctic, aerial surveys

RÉSUMÉ. On a réalisé en même temps des photos aériennes et des images obtenues par capteur thermique infrarouge (10,6 $\mu \mathrm{m})$, de morses échoués sur la glace de mer du bassin de Foxe, dans les Territoires du Nord-Ouest au Canada. Les données thermiques infrarouges numériques obtenues grâce à l'appareil infrarouge à vision vers l'avant (FLIR) fournissent une méthode d'estimation du nombre de morses, vu que les objets (groupes de morses) ont une température notablement plus élevée que leur arrière-plan (océan et glace de mer). On a procédé à une régression linéaire par la méthode des moindres carrés entre le nombre d'objets comptés sur les clichés et le nombre de pixels de l'image thermique infrarouge du même site, et on a prédit une estimation de la taille du groupe à partir du nombre de pixels représenté par chaque groupe.

Les résultats révèlent que la technique de l'image thermique analogue fournit un moyen efficace pour obtenir une variable de stratification qui puisse ultérieurement entrer dans la conception de relevés. On évalue l'approche visant à estimer le nombre de morses à l'aide du radar FLIR en se concentrant sur la reproductibilité de l'expérience, à la fois en ce qui concerne les appareils de mesure et en tenant compte d'une gamme limitée de conditions environnementales. On évalue ensuite la précision de l'estimation du nombre de morses à partir du radar FLIR par rapport à celle du dénombrement par clichés.

Le nombre de morses obtenu à l'aide de l'image thermique numérique sur une bande échantillon de $1778 \mathrm{~m}$ est aussi précis que celui provenant de trois dénombrements indépendants faits à partir de clichés sur une bande échantillon de $686 \mathrm{~m}$. Avec cette configuration, la technique utilisant le FLIR permettrait donc d'augmenter le taux d'échantillonnage (en surface) de 160 p. cent. En s'appuyant sur ces résultats, nous recommandons une approche stratifiée pour l'estimation de la population des morses, approche qui ferait intervenir les techniques de dénombrement à l'aide d'un capteur thermique infrarouge, parallèlement aux techniques visuelles et photographiques.

Mots clés: morse, télédétection thermique infrarouge, Arctique canadien oriental, relevés aériens

Traduit pour le journal par Nésida Loyer.
\end{abstract}

\section{INTRODUCTION}

In the Canadian Arctic, walrus are a resource facing pressure from an increasingly large native population, whose expectations for development rely heavily on wildlife. Presently, stocks of walrus are thought to be stable with harvest levels sustainable, but information on stock size and trend is limited (Richard and Campbell, 1988). Assessment of walrus stocks is essential to guide future management of the native harvest and to monitor stock response to perturbations in the arctic marine ecosystem.

Walrus population assessment is complicated by the gregarious nature of these animals. Walrus congregate in groups when hauled out on pack ice, and therefore samples of walrus density are often highly variable (Estes and Gilbert, 1978). Aerial censusing is the most appropriate method for obtaining population estimates. The difficulties for visual surveyors are, first, to locate walrus groups over large expanses of ice (fatigue and boredom) and, second, to accurately enumerate these groups when they contain from one to several hundred animals (finite counting time per group). Photographic surveys can minimize the counting problems but they are only practical and affordable if sampling schemes can be implemented to reduce survey costs. In most cases, the problems described above lead to imprecise or very costly walrus population surveys.

The scientific rationale for thermal remote sensing of walrus is based on the premise that all objects above absolute zero $\left(-273.2^{\circ} \mathrm{C}\right)$ emit electromagnetic radiation. If a body emits a maximum amount of energy at the given temperature, then the object is considered a black body radiator, which has an emissivity of one. Most earth objects have emissivities between zero and less than one. The relationship between the temperature of an object and the amount of radiation emitted at each wavelength can be described by Plank's Law. This law states that as the surface temperature of an object decreases, the peak wavelength emitted increases and the total radiant energy decreases (peak moves right and area under the curve decreases; Fig. 1). At $6000^{\circ} \mathrm{K}$ the sun has a peak spectral emittance at visual wavelengths. Very hot objects

\footnotetext{
${ }^{1}$ Earth Observations Laboratory, Institute for Space and Terrestrial Science, University of Waterloo, Ontario, Canada N2L 3G1

${ }^{2}$ Department of Fisheries and Oceans, Fish and Marine Mammal Management Section, Winnipeg, Manitoba, Canada R3T 2N6

${ }^{3}$ Electromagnetic Sensing and Interpretation (E.M.S.I.), 3 Aspenwood Place, Winnipeg, Manitoba, Canada R2G 3Z9

(C) The Arctic Institute of North America
} 


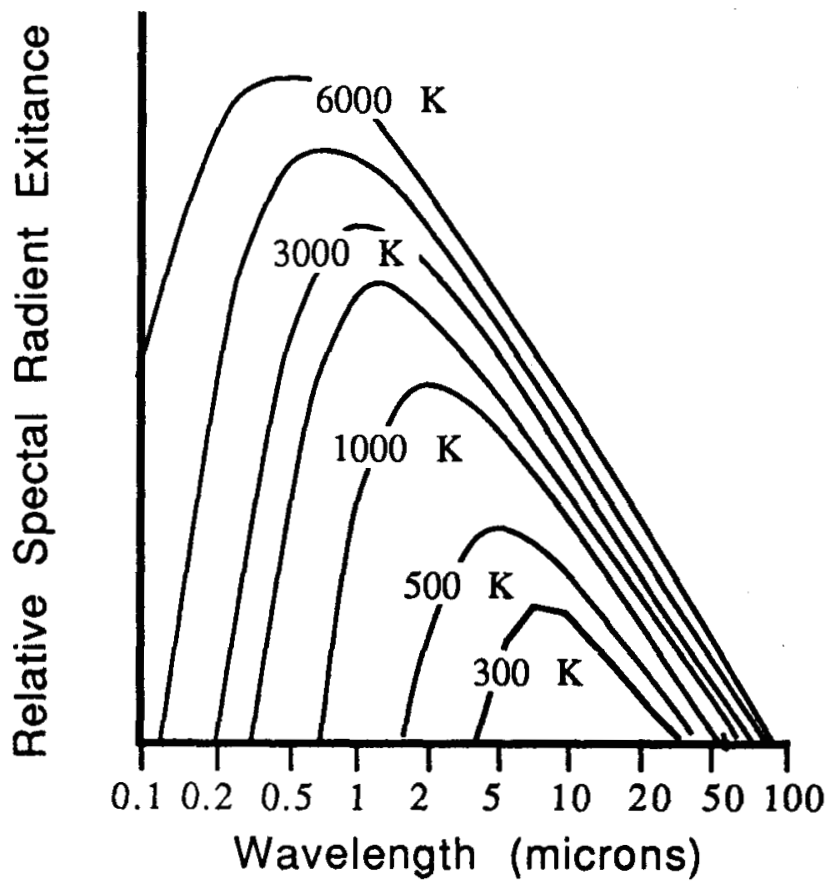

FIG. 1. Relationship between emittance and wavelength at different object temperatures $(\mathrm{K}=$ degrees Kelvin).

$\left(500^{\circ} \mathrm{K}\right)$ have a peak emittance at $\sim 6.0$ to $\sim 7.0 \mu \mathrm{m}$ and objects on the earth's surface $\left(300^{\circ} \mathrm{K}\right)$ have a peak emittance at $\sim 9.0$ to $\sim 11.5 \mu \mathrm{m}$.

If we lived in a vacuum it would be a simple task to identify and describe features based on emittance of this energy. In the real world the atmosphere interferes with propagation of electromagnetic radiation. Remote sensing technology takes advantage of atmospheric windows that are areas of decreased attenuation. Primary windows are located at visual wavelengths, middle infrared and thermal infrared. Infrared film operates because the visual window extends to the near infrared range $(\sim 0.7$ to $1.1 \mu \mathrm{m})$. Forest managers often use middle infrared ( $\sim 4.0$ to $7.0 \mu \mathrm{m}$ ) radiation for identification of hot spots during fire cleanup. The thermal infrared window is located at approximately 9.0 to $11.5 \mu \mathrm{m}$ and provides a window where detection of objects at earth temperatures is possible.

Prior success involving thermal detection of terrestrial species was largely determined by the magnitude of the thermal contrast exhibited by the species versus background and whether electromagnetic sensitivities were centred on the middle or thermal infrared windows. Particular cases have shown that the temperature differential responsible for this contrast is susceptible to wide fluctuations. Factors such as surface and solar radiation fluxes, air temperature and wind speed are responsible for changes in the surface radiative temperature of animals (Moen and Jacobsen, 1974) and therefore influence detection. The radiative thermal properties of the wildlife habitat are also important. The magnitude of thermal contrast between animal and background is favourable for remote detection where relatively cool background conditions prevail (Burkhalter and Kientz, 1984; Lavigne et al., 1975).

Prior attempts involving thermal detection of walrus provide encouraging results using thermal infrared wavelengths. The high thermal contrast between walrus and the surrounding habitat is primarily due to the physiological response (vasodilation) of walrus to warm ambient air temperatures (Ray and Fay, 1968) compared with a uniformly cool background surface provided by their haul-out ice habitat (Wartzok and Ray, 1975). Practicalities of population assessment were realized when detection limits were estimated at $1524 \mathrm{~m}$ (Ray and Wartzok, 1976) and $3048 \mathrm{~m}$ (Barber et al., 1989b). When conditions are appropriate for aerial surveys (clear sky and low wind velocities) walrus are at or near peak surface radiative temperatures compared with their background. The gregarious nature of walrus allows highaltitude detection, since large groups produce a strong objectto-background ratio or thermal signature.

The primary objective of this analysis is to determine the effectiveness of digital FLIR imagery for estimating walrus group size for animals hauled out on floating sea ice. Pursuant to this objective we pose five research questions: 1) Can the FLIR be used to obtain a stratification variable? 2) Are the mechanics of this technique reproducible? 3) What is the effect of range to target on precision? 4) Can digital image analysis enhance our predictive capabilities? and 5) How does the precision of the FLIR method compare with precision of photo interpretation? Throughout our analysis we consider precision as the standard of comparison between FLIR estimation and photo counts. This is because accuracy requires knowledge of the true number of walrus present (i.e., an unknown parameter).

\section{METHODS}

\section{Data Collection}

On 25 July 1989, we obtained airborne thermal imagery and photographs of walrus hauled out on ice in Foxe Basin, Northwest Territories (N.W.T.) (Fig. 2), using the Department of Fisheries and Oceans Remote Sensing System (Yaremchuk and Barber, 1985). Thermal data were collected with a Forward Looking Infrared (FLIR) thermal imager (peak wavelength $=-10.6 \mu \mathrm{m}$ ). The FLIR provides real-time display on a video monitor and signal recording on a VHS video cassette recorder (VCR). The FLIR is housed in a specially designed nose cone of a DeHavilland Twin Otter and can be adjusted at angles from $10^{\circ}$ to $90^{\circ}$ (down) from the flight plane. Photography was obtained using a $229 \mathrm{~mm}$ format mapping camera with Kodak Aerocolor Negative (type 2445) film.

During the experimental flight, the FLIR was adjusted at a $20^{\circ}$ depression angle (Fig. 3). With horizontal and vertical fields of view of $28^{\circ}$ and $17^{\circ}$, this viewing angle resulted in a keystone-shaped image of the ocean surface. A $20^{\circ}$ depression angle was selected as optimal to avoid detection of sky emissivities yet maximize swath width. At the centre of the keystone (principal point) the swath width (perpendicular to flight direction) ranges from $444 \mathrm{~m}$ at a $305 \mathrm{~m}$ flight altitude to $4444 \mathrm{~m}$ at a $3048 \mathrm{~m}$ flight altitude. FLIR swaths are computed using (1) and are provided for nearrange $\left(\alpha=61.5^{\circ}\right)$, mid-range $\left(\alpha=70^{\circ}\right)$ and far-range $\left(\alpha=78.5^{\circ}\right)$. We use the term "range" to denote distance from sensor to principal point of the oblique image and altitude for flying height of the aircraft (Fig. 3).

$$
2 *\left(\tan \left(0.5^{*} 28^{\circ}\right) * \frac{\text { Altitude }}{\cos \alpha}\right), \alpha \text { is } 70^{\circ} \text { at the mid-range. }
$$

Several repeat passes were flown over walrus hauled out on sea ice in Foxe Basin (Fig. 2). Photo passes were conducted 


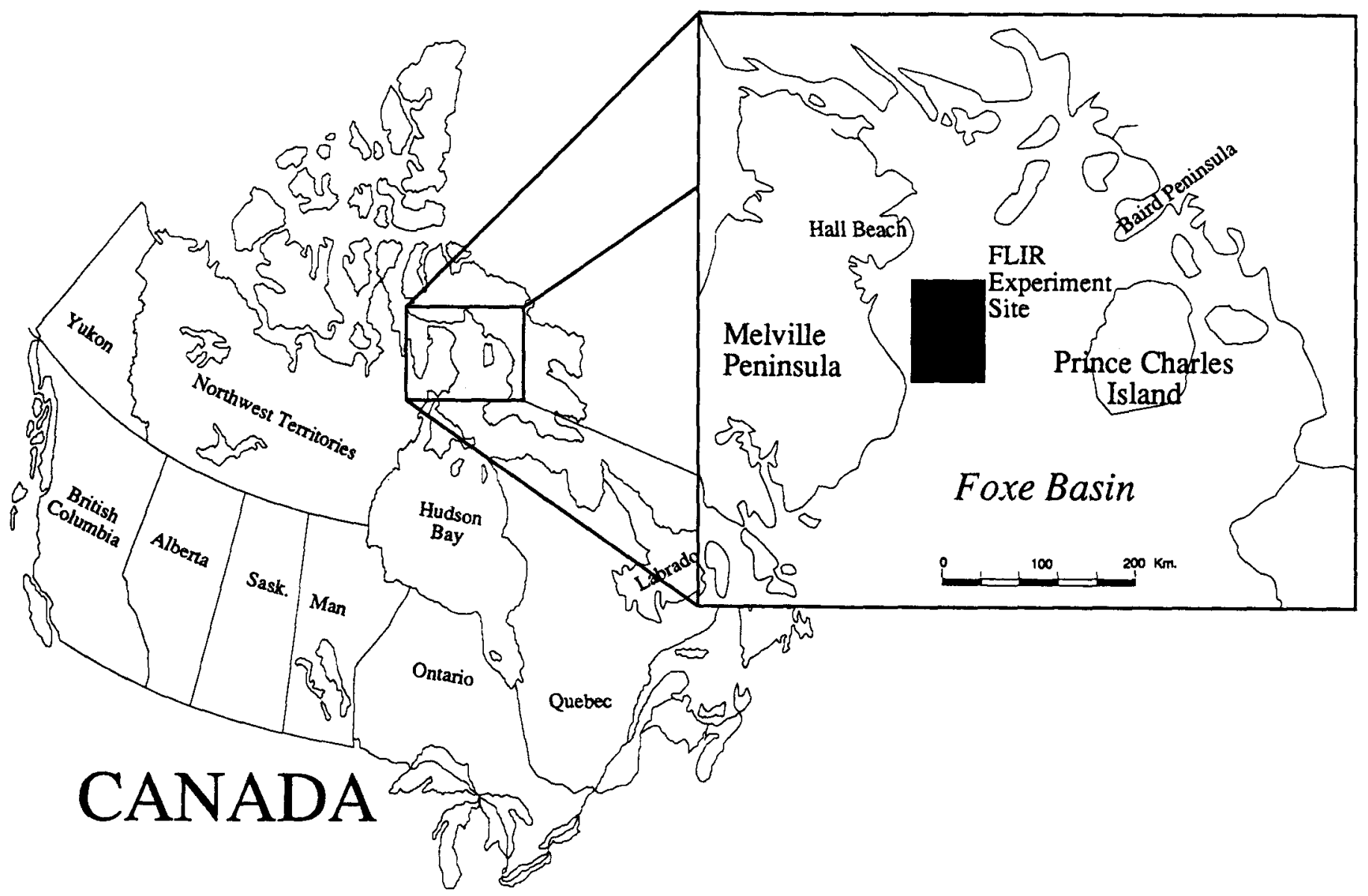

FIG. 2. FLIR experiment site, Foxe Basin, N.W.T.

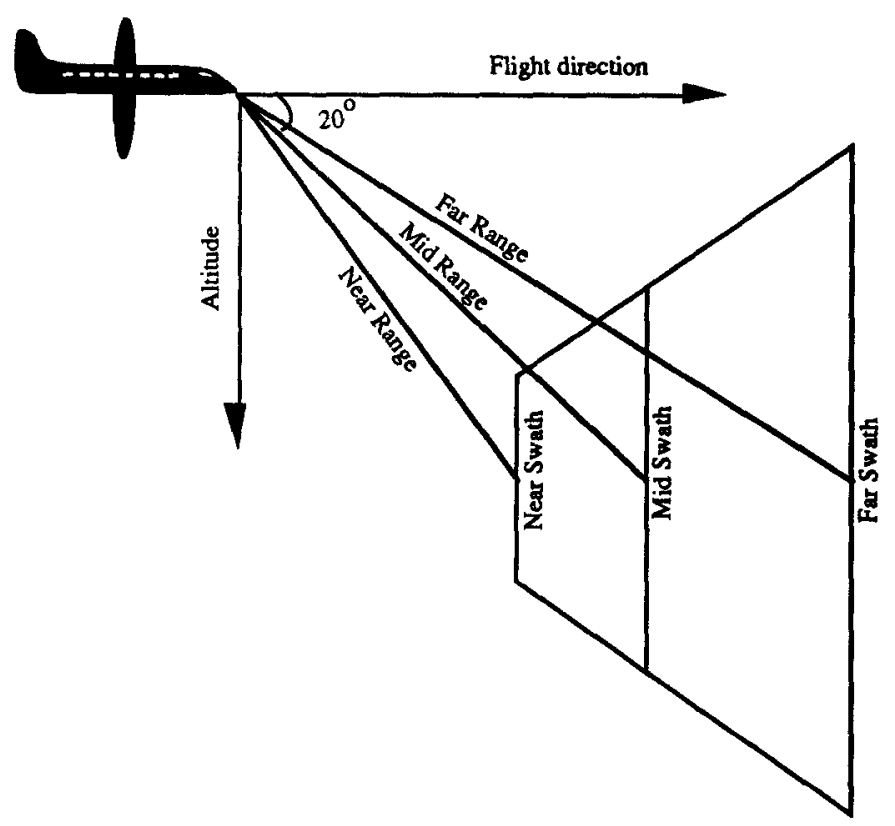

FIG. 3. Terminology used to denote the oblique viewing angle of the FLIR. Image shows altitude, range, flight direction, incidence angles and the keystone-shaped image obtained at oblique viewing angles ( $\mathrm{Gl}=$ digital grey level ranging from 0 to 255 ).

at $457 \mathrm{~m}$ to obtain photography at a scale appropriate for counting walrus. FLIR imagery was acquired concurrent with the photo pass $(457 \mathrm{~m}$ ) and at $1219 \mathrm{~m}$ and $2428 \mathrm{~m}$ altitudes. Walrus groups detected on the FLIR imagery were identified on the corresponding photographs. At the time of the survey, walrus were subjected to direct solar illumination and winds were calm, which combined to create a warm ambient temperature $\left(\sim 6^{\circ} \mathrm{C}\right)$. Although the exact magnitude of the surface irradiance is unknown, we consider these microclimate conditions typical of summer survey conditions encountered during our 1988, 1989 and 1990 aerial surveys in this region.

\section{Data Extraction}

The FLIR video records were digitized on a Macintosh II (Apple Computer) using a DT2255 QuickCapture (Data Translation Inc.) video board. The board captures a $640 \times$ 480 pixel frame at an 8 bit dynamic range (i.e., grey levels from 0 to 255). Each walrus group was sampled 15 times. Five samples of each discrete emittance group were obtained at near, mid- and far ranges. This sampling scheme allowed simultaneous assessment of the replicability of the frame grabber (mechanics of the process) and the impact of range distance on calibration of the FLIR emittance data to walrus counts. Not all group sizes could be extracted at all ranges.

The digitized imagery were interpreted using Mac II image analysis software (Barber et al., 1989a). Walrus thermal emissions appear as bright objects on a relatively homogeneous background (Fig. 4A). By examining digital brightness values (Bv) in a three-dimensional plot (Fig. 4B), it was possible to isolate the walrus emissions (object) from 


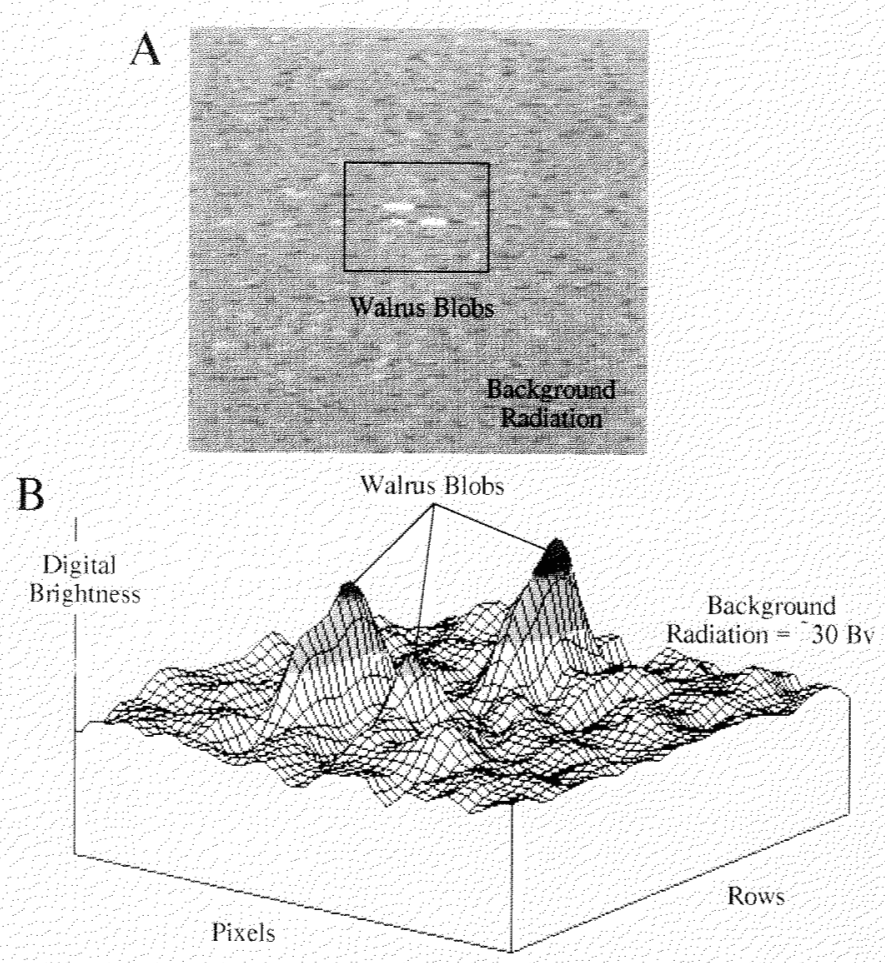

FIG. 4. Thermal emittance from walrus. Image shows three distinct blobs with walrus present. Digital imagery is scaled from 1 to 256 . Frequency of pixels within the blob (thresholding isolates only those pixels within the blobs) are used to predict walrus counts.

the background using a thresholding technique. Thresholding is a digital image analysis operation whereby the digital values of the background are incrementally set to a common grey level until only the objects (walrus groups) remain in the image. The decision rule is that the iterations continue until one step before a pixel within the walrus group is coded as a background pixel.

Summary statistics within the threshold region (number of pixels, mean brightness and standard deviation of the brightness) were extracted by computer. To assess the impact of digital image analysis techniques, two convolution filtering operations - a $3 \times 3$ low pass filter (to reduce image noise) and a $3 \times 3$ low pass filter followed by a $3 \times 3$ high pass filter (which increases object detail while suppressing background variation) - were computed. For more details on convolution processing see Richards (1986).

Photo interpretation was conducted by three different people. Each interpreter conducted counts independent of one another (to determine the precision of the photo counts) and independent of the results obtained from the FLIR interpretation. Counting sessions were controlled to minimize the effect of fatigue and boredom on, within and between photo interpreter replicability. Interpreters read film for a maximum of two hours per session and a maximum of two sessions per day. All animals detected were identified as adult walrus.

\section{Data Analysis}

To determine whether FLIR data could be used to obtain a stratification variable, the minimum group size recorded by the three photo interpreters was plotted against flying altitude (Fig. 5). This relationship shows the minimum number of animals detectable under different range-to-target and swath widths available with the FLIR (Table 1).

Reproducibility is an important prerequisite to determining whether data from the digital FLIR imagery can be used to predict walrus group size. This requires that given the same walrus group we should obtain a statistically equivalent output from the calibrated FLIR data, regardless of replicate or environmental condition. To provide a meaningful assessment we require that the regression models developed to predict walrus counts from thermal emittance statistics be equivalent at each replicate within a particular altitude and range. The impact of a full range of environmental conditions on replicability cannot be adequately assessed using these data since we sampled only under a limited range of conditions.

A Multivariate General Linear Test (GLT; Wilkinson, 1987) was used to determine whether the five regression models (one for each replicate at each range and altitude) were statistically equivalent. Least squares linear regressions were computed using the square root of the pixel counts within each emittance group and the square root of the average walrus group size, obtained from the three photo counts. The square root of pixel count and average walrus photo count were computed to meet the assumption of homoscedasticity in this general linear model. The model I least squares linear regression also assumes that the independent variable is nonstochastic. Within the limitations of this analysis we consider that the average walrus count meets this assumption.

An interaction term ("Interaction" in Tables 2-4) was computed between replicates and the square root of the frequency of pixels within each group to determine whether the

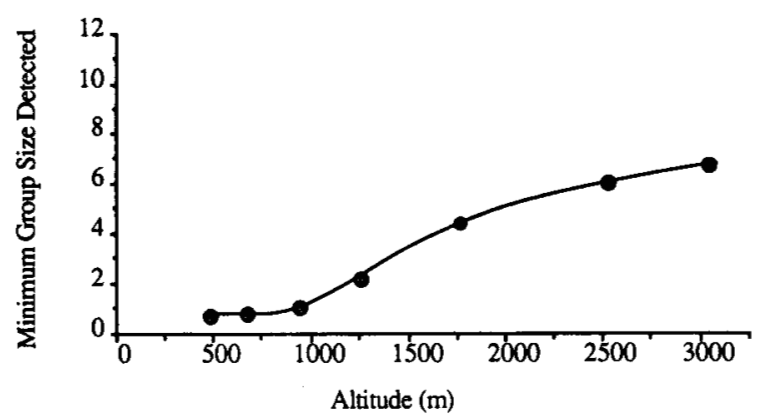

FIG. 5. Minimum group size detectable on FLIR imagery relative to flight altitude.

TABLE 1. Relationship among altitude, range and swath widths of a $20^{\circ}$ oblique-viewing FLIR (notations are consistent with Fig. 3; computations are based on equation [1])

\begin{tabular}{lrrrr}
\hline \hline & \multicolumn{4}{c}{ Altitude (m) } \\
\cline { 2 - 5 } & 457 & 1219 & 2438 & 3048 \\
\hline Near-range & 958 & & \multicolumn{4}{c}{ Range (m) } \\
Mid-range & 1337 & 3565 & 5110 & 6388 \\
Far-range & 2293 & 6115 & 7129 & 8912 \\
& & \multicolumn{4}{c}{ Swath (m) } \\
Near-swath & 478 & 12231 & 15289 \\
Mid-swath & 667 & 1778 & 2548 & 3185 \\
Far-swath & 1144 & 3049 & 3555 & 4444 \\
\hline \hline
\end{tabular}


TABLE 2. Results of $457 \mathrm{~m}$ near-, mid- and far-range replicate comparisons of the least squares regression models

\begin{tabular}{|c|c|c|c|c|c|}
\hline Source & $\begin{array}{c}\text { Sums of } \\
\text { squares }\end{array}$ & $\begin{array}{l}\text { Degrees of } \\
\text { freedom }\end{array}$ & $\begin{array}{r}\text { Mean } \\
\text { squareE }\end{array}$ & F ratio & $P$ value \\
\hline \multicolumn{6}{|c|}{$457 \mathrm{~m}$ altitude, near-range $(958 \mathrm{~m})$} \\
\hline Replicate & 0.514 & 4 & 0.129 & 0.280 & 0.891 \\
\hline SQRT(pixel) & 409.255 & 1 & 409.255 & 890.421 & 0.000 \\
\hline Interactions & 0.868 & 4 & 0.217 & 0.472 & 0.756 \\
\hline Error & 88.707 & 193 & 0.460 & & \\
\hline \multicolumn{6}{|c|}{$457 \mathrm{~m}$ altitude, mid-range $(1337 \mathrm{~m})$} \\
\hline Replicate & 0.233 & 4 & 0.058 & 0.100 & 0.983 \\
\hline SQRT(pixel) & 382.566 & 1 & 382.566 & 653.256 & 0.000 \\
\hline Interactions & 0.314 & 4 & 0.078 & 0.134 & 0.970 \\
\hline Error & 117.126 & 200 & 0.586 & & \\
\hline \multicolumn{6}{|c|}{$457 \mathrm{~m}$ altitude, far-range $(2293 \mathrm{~m})$} \\
\hline Replicate & 0.624 & 4 & 0.156 & 0.153 & 0.961 \\
\hline SQRT(pixel) & 161.568 & 1 & 161.568 & 158.531 & 0.000 \\
\hline Interactions & 0.291 & 4 & 0.073 & 0.071 & 0.991 \\
\hline Error & 91.724 & 90 & 1.019 & & \\
\hline
\end{tabular}

TABLE 3. Results of $1219 \mathrm{~m}$ near- and mid-range replicate comparisons of the least squares regression models

\begin{tabular}{|c|c|c|c|c|c|}
\hline Source & $\begin{array}{l}\text { Sums of } \\
\text { squares }\end{array}$ & $\begin{array}{l}\text { Degrees of } \\
\text { freedom }\end{array}$ & $\begin{array}{c}\text { Mean } \\
\text { squareE }\end{array}$ & $F$ ratio & $P$ value \\
\hline \multicolumn{6}{|c|}{$1219 \mathrm{~m}$ altitude, near-range $(2555 \mathrm{~m})$} \\
\hline Replicate & 2.509 & 4 & 0.627 & 1.124 & 0.348 \\
\hline SQRT(pixel) & 118.691 & 1 & 118.691 & 212.676 & 0.000 \\
\hline Interactions & 2.148 & 4 & 0.537 & 0.962 & 0.431 \\
\hline Error & 72.551 & 130 & 0.558 & & \\
\hline \multicolumn{6}{|c|}{$1219 \mathrm{~m}$ altitude, mid-range $(3565 \mathrm{~m})$} \\
\hline Replicate & 0.250 & 4 & 0.062 & 0.127 & 0.972 \\
\hline SQRT(pixel) & 04.285 & 1 & 104.285 & 212.606 & 0.000 \\
\hline Interactions & 0.195 & 4 & 0.049 & 0.099 & 0.982 \\
\hline Error & 49.051 & 100 & 0.491 & & \\
\hline
\end{tabular}

TABLE 4. Results of $2438 \mathrm{~m}$ near- and mid-range replicate comparisons of the least squares regression models

\begin{tabular}{lccrrr}
\hline \hline Source & $\begin{array}{c}\text { Sums of } \\
\text { squares }\end{array}$ & $\begin{array}{c}\text { Degrees of } \\
\text { freedom }\end{array}$ & $\begin{array}{c}\text { Mean } \\
\text { squareE }\end{array}$ & F ratio & P value \\
\hline \multicolumn{7}{c}{$\begin{array}{c}\text { Replicate } \\
2438 \mathrm{~m} \text { altitude, near-range }(5110 \mathrm{~m})\end{array}$} \\
SQRT(pixel) & 1.650 & 4 & 0.413 & 0.295 & 0.880 \\
Interactions & 146.960 & 1 & 146.960 & 105.266 & 0.000 \\
Error & 1.932 & 4 & 0.483 & 0.346 & 0.846 \\
\multicolumn{7}{c}{} & 139.609 & 100 & 1.396 & & \\
Replicate & $2438 \mathrm{~m}$ altitude, mid-range (7129 m) & \\
SQRT(pixel) & 1.383 & 4 & 0.346 & 0.166 & 0.955 \\
Interactions & 49.241 & 1 & 49.241 & 23.674 & 0.000 \\
Error & 1.409 & 4 & 0.352 & 0.169 & 0.953 \\
\hline \hline
\end{tabular}

digitization technique was statistically reproducible. Computation of the GLT consists of several steps. First, a full model is fit for each of the five replicates; a reduced model is then fit to the combined data set, pooling all sample points from the five replicates; an F-statistic, involving the difference in the sum of the squared error terms for the reduced model minus the full model (2) is then used to test whether or not the regressions from each of the five replicates are statistically equivalent. The test hypothesis can be more formally stated as: Ho: The slopes and/or intercepts of the five regression models are equal. Ha: The slopes and/or intercepts of the five regression models are not equal.

$$
F_{S t a t}=\left\{\frac{\left(S S E_{R}-S S E_{F}\right) \div\left(d f_{R}-d f_{F}\right)}{S S E E_{F} \div d f_{F}}\right\}
$$

where $\mathrm{SSE}_{\mathrm{R}}$ is the sums of squares due to error for the reduced model (all five replicates considered simultaneously); $\mathrm{SSE}_{\mathrm{F}}$ is the sums of squares due to error from the full model (SSE from each of the replicates computed separately, then summed); df refers to the degrees of freedom for the reduced and full models.

We conducted two forms of digital image enhancement (see Data Extraction). An average of the five replicates for the square root of the pixel counts were regressed against the average square root of the walrus counts within the midrange, at 457, 1219 and $2438 \mathrm{~m}$ altitudes. This is denoted as the "RAW" (i.e., unprocessed data) variable in Figure 6. The two processed variables are the pixel counts within the walrus emittance groups after "HIGHPASS" and "LOWPASS" filters were applied. A relative measure of the impact of this processing (coefficient of determination, obtained from the regression models) is presented in Figure 6 as a function of range to target.

As with most remote censusing techniques, the approach described here provides two "relative" measures of walrus abundance: photo counts and calibrated FLIR estimates. For the purpose of comparison, the between photo interpreter (three counters) variability was computed as the maximum minus minimum count (Fig. 7A) for each walrus group. These data represent the deviations from agreement (zero line) among the three photo interpreters. A comparable measure for the FLIR data (Figs. 7B,C,D) for three ranges (1337, 3565 and $7129 \mathrm{~m}$ ) shows the absolute difference between observed (average of the three photo counts) and predicted (estimated $Y$ from the regression model). These data represent the deviations from agreement (zero line) between an estimate of the true number of walrus present (average of the three photo counts) and calibrated FLIR estimates at each range.

To provide a quantitative representation of the relative differences between photo interpreter variability and calibrated FLIR estimation, we compared the distribution of deviations (i.e., distribution of deviations from each scatter point in Figure 7 to the zero or agreement line) between the photo counts (Fig. 7A) and each of the calibrated FLIR estimates (Figs. 7B-D), using a Kolmogorov-Smirnov test. This non-parametric test compares the differences in the distributions of deviations and determines whether each can

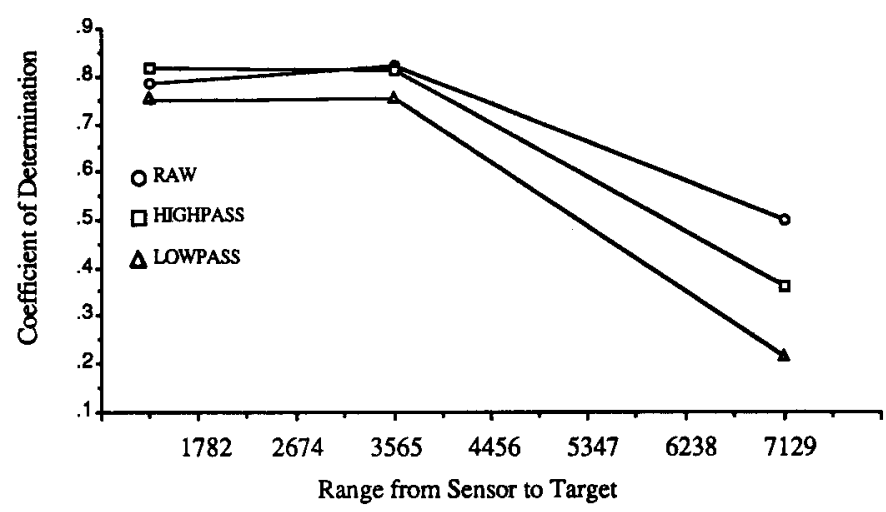

FIG. 6. Coefficient of determination for three image-processing techniques (Raw [unprocessed], Highpass, and Lowpass) at three different range-totarget distances. Coefficients are from the least squares estimate using square root of pixel and walrus counts. 


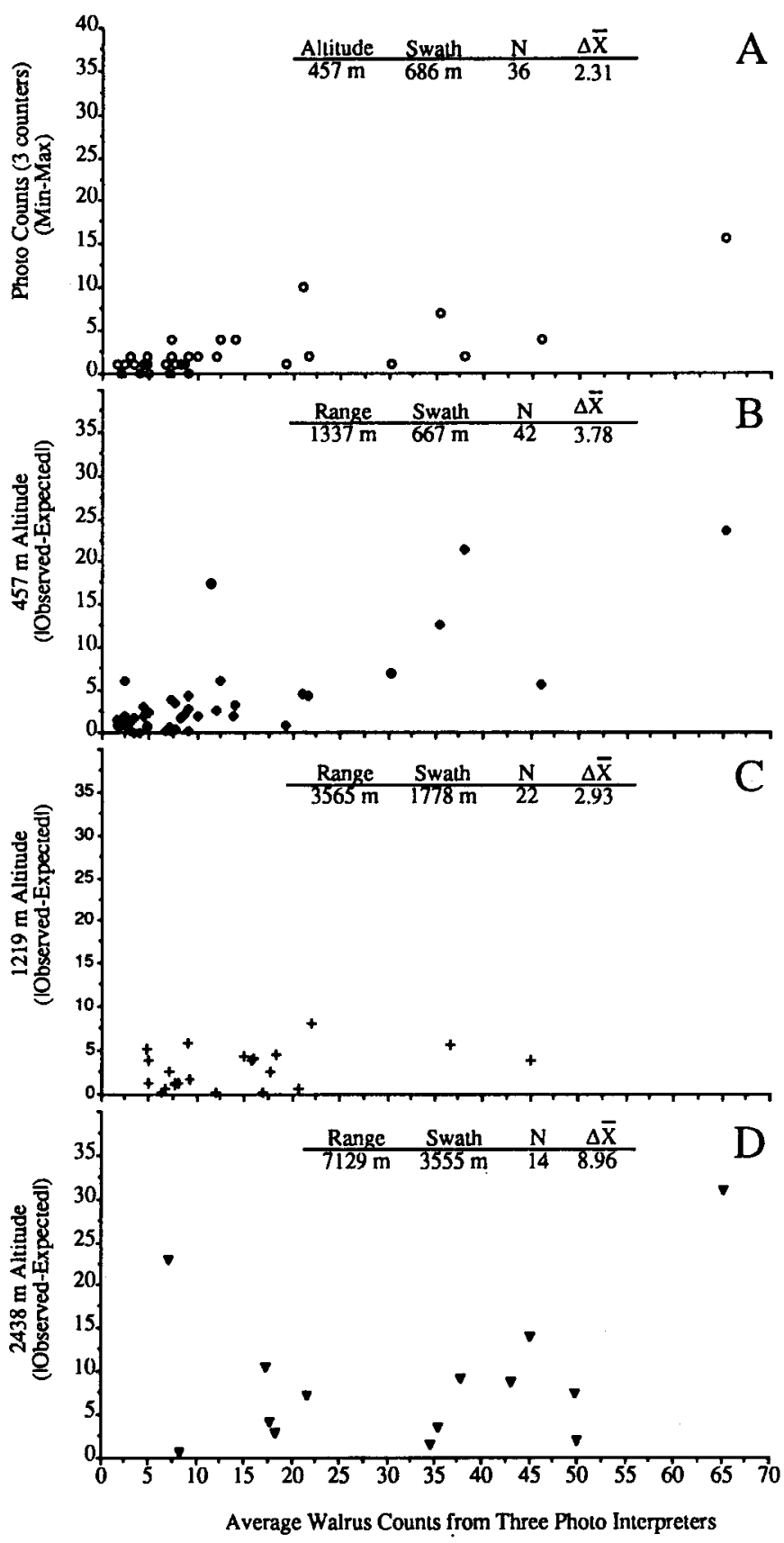

FIG. 7. Differences between maximum and minimum photo counts from the three photo interpreters (A) and absolute differences, observed at the midrange, between observed (average of the three photo counts) and expected (predicted counts from the regression models) walrus counts at $457 \mathrm{~m}(\mathrm{~B})$, $1219 \mathrm{~m} \mathrm{(C)}$ and $2438 \mathrm{~m}(\mathrm{D})$ altitudes.

be considered to arise from a common population. A nonparametric approach was selected because the distribution of deviations from zero (i.e., precision) did not meet the assumptions of an equivalent parametric test.

\section{RESULTS AND DISCUSSION}

The minimum group size detectable at each range is sufficiently small for stratification purposes (Fig. 5). At higher altitudes (or ranges of $\sim 3 \mathrm{~km}$ ) minimum detectable group sizes are less than 10 animals. Swath widths at these altitudes $(>7 \mathrm{~km}$ at the far swath, Table 1) allow the large aerial coverage required for preliminary surveys meant to be used for stratification. Clear skies are the only optimal imaging condition. The object-to-background emittance ratios are sufficiently large, even at long range, that downwelling longwave radiation from high overcast conditions does not preclude application of this technique. Collection of the stratification variable can be conducted at low sun angles (i.e., early morning or late in the day).

The mechanics of the FLIR digitization technique are reproducible since the $F$ ratios for the "Interactions" (Tables 2-4) are non-significant, confirming that neither slope nor intercept of these regression models is statistically different. There exists a strong linear relationship between the square root of pixel counts and average walrus group size ("SQRT(Pixel)" in Tables 2-4). The F statistics for the SQRT(Pixel) variables in Tables 2-4 also provide a measure of precision as a function of range to target. As the F statistic increases, so does the precision of the resulting linear regression model.

The replicability of this technique requires that a constant walrus group imaged at a constant range but under different atmospheric conditions produce a statistically equivalent estimate from the calibrated FLIR data. The operational impacts of variable microclimatic conditions will be most acute in the high-altitude data collection. The exact impacts of the range of acceptable conditions at these high altitudes requires further research. Since the lower altitude data are collected coincident with photography, the calibration of FLIR records to photographic counts will encompass climate variability within the calibration model. Given that the conditions must be optimal for the survey to be conducted (either clear or very high overcast conditions with calm winds), we consider variability attributable to ambient atmospheric conditions to be minimal.

A related problem is the variability in vasodilation of hauled out animals. Surface measurements of walrus skin temperatures, obtained coincident with our overflights, confirm that walrus reach a temperature detectable by the FLIR within minutes of hauling out. To illustrate, one particular animal warmed from $6^{\circ} \mathrm{C}$ to $20^{\circ} \mathrm{C}$ within $6 \mathrm{~min}$ of hauling out (S. Innes, pers. comm. 1990). The impact of integrated thermal emittance as a function of group size and group dispersion and, in particular, these parameters as a function of microclimatic conditions require further surface validation.

Once the FLIR imagery is in digital form there are a variety of image enhancement techniques available to reduce noise within the digital data. In this analysis there appears to be no significant improvement in our predictive capability using either a high pass or low pass filtering algorithm (Fig. 6). In future analysis we plan to utilize other image enhancement techniques and assess the utility of multivariate prediction (i.e., mean grey level, pixel count, frequency distribution of grey levels, etc.) of walrus counts from the calibrated FLIR data.

The final aspect of our analysis is a relative comparison of photo counts and FLIR estimates based on the precision of each technique. The mean absolute deviation $(\Delta X)$ provides a relative measure of agreement (precision) among the three photo counts (Fig. 7A) and three altitudes of calibrated FLIR data (Figs. 7B-D). The most precise techniques are the photo counts and the $1219 \mathrm{~m}$ FLIR estimates (lowest mean deviations). Statistically, there is no difference among the 
photo counts, $457 \mathrm{~m}$ FLIR and $1219 \mathrm{~m}$ FLIR distribution of deviations (Table 5). Among the three altitudes, it appears that calibrated FLIR data collected at $1219 \mathrm{~m}$ (Fig. 7C) provided the most precise FLIR data set (relative to the photo counts). We speculate that this result is a function of the sensitivity of the FLIR data to variations in walrus density. At $457 \mathrm{~m}$ the within-group variations are larger due to the natural variation in walrus density within a particular group. At 1219 $m$ this variation is averaged, since the area covered by the FLIR instantaneous field of view (IFOV, or area covered by a single pixel) is larger.

TABLE 5. Kolmogorov-Smirnov test of the distribution of differences between the photo count maximum minus minimum and the absolute difference between the FLIR estimated minus observed number of walrus

\begin{tabular}{lccc}
\hline \hline Parameter & 1337 m range & $3565 \mathrm{~m}$ range & $7129 \mathrm{~m}$ range \\
\hline $\mathrm{df}$ & 2 & 2 & 2 \\
$\mathrm{~N}$ (Photo Max-Min) & 36 & 36 & 36 \\
$\mathrm{~N}$ (FLIR Obs-Exp) & 42 & 22 & 14 \\
$\mathrm{D}_{\max }$ & 0.282 & 0.351 & $0.591^{*}$ \\
$\mathrm{D}_{0.05}$ & 0.308 & 0.368 & 0.428 \\
\hline \hline
\end{tabular}

* Kolmogorov-Smirnov statistic is significant at $\alpha=0.05$.

\section{CONCLUSIONS}

Data from the FLIR can be used to establish the location of walrus hauled out on ice. We expect detection of a minimum group size of one at altitudes less than $1000 \mathrm{~m}$ and of groups less than ten up to altitudes of approximately $4000 \mathrm{~m}$ (assuming a $20^{\circ}$ depression angle). Imaging conditions require a dry air mass, high-altitude thin overcast or clear skies with low surface wind velocities. The digitizing process provides a sufficiently reproducible output to allow estimation of walrus abundance from the number of pixels within a particular thermal emittance group. The trade-off between sampling fraction and precision is optimal at an altitude of $1219 \mathrm{~m}$. We conclude that the $457 \mathrm{~m}$ and 1219 $\mathrm{m}$ altitude FLIR estimates are as precise as photo interpretation over the conditions encountered in this empirical experiment.

Although we never intended to conduct regressions at the $457 \mathrm{~m}$ altitude, during our analysis we found that emittance groups identified by the FLIR interpreter were not subsequently found by the photo interpreters. Re-examination of the photographs showed, without exception (i.e., no false positives), a single walrus, or perhaps a pair, was missed by the photo interpreters. In total, 36 groups were detected by the photo interpreters and $\mathbf{4 2}$ groups with the FLIR. This result contrasts with the pioneering work of Ray and Wartzok (1980), who found that thermal imagery did produce false positives, but agrees with their findings that thermal data could detect small groups (1-10 animals) missed by the photo interpreters.

Based on the results described here, we suggest a sampling scheme where a high-altitude survey is conducted to collect a stratification variable. An altitude between 2438 and 3048 $\mathrm{m}$ would be optimal. From observations made during aerial surveys in Foxe Basin in 1988, 1989 and 1990, we found that walrus tended to concentrate near the interface between floating ice and open water. A complete coverage of this habitat could be conducted in a single three-hour flight. Once the stratification data were obtained, a mid-altitude survey (e.g., $1219 \mathrm{~m}$ ) would be conducted, where sampling effort is apportioned according to the stratification survey. Finally, photo passes would be conducted at $457 \mathrm{~m}$ using systematic transects placed over the walrus concentration areas, both as a means of obtaining a systematic photo estimate and for FLIR calibration. We suggest a FLIR pass at the $1219 \mathrm{~m}$ altitude because a larger coverage can be realized with the same precision available at the $457 \mathrm{~m}$ altitude.

FLIR imagery at each altitude would be converted to digital form and calibrated using regressions between photo counts and thermal emittance statistics. This would result in three independent samples of the population: one from the FLIR high-altitude stratification pass, one from the FLIR midaltitude pass, and one from the photographic pass at 457 $\mathrm{m}$. The low-altitude FLIR imagery can also be used to ensure that the photo interpreters successfully identify all walrus groups.

We conclude that sensing walrus emittance is an effective means of obtaining a priori information on distribution. The calibrated digital FLIR imagery provides a cost-effective means of obtaining a population count because of the much larger sampling fraction that is obtained compared with photographic coverage. Over time, an empirical relationship will be formalized that will allow calibration of FLIR imagery at different ranges and under a few different microclimatic conditions. Throughout this development we recommend that thermal wavelength imagery be used in combination with traditional aerial photographic and visual survey methods for population assessment of walrus inhabiting sea ice.

\section{ACKNOWLEDGEMENTS}

This research was supported by the Department of Fisheries and Oceans, Winnipeg, Manitoba. We wish to acknowledge the assistance of Sean Reddan, Blair Dunn, Stuart Innes and David Lavigne for a variety of contributions; Dan Pike and the Polar Continental Shelf Project (Energy Mines and Resources, Canada) for field support; and Andries Blouw for contributions throughout this project. Partial support for analysis was provided through a Centre of Excellence grant from the Province of Ontario through the Institute for Space and Terrestrial Science (ISTS) and an NSERC Operating Grant to Dr. E. LeDrew. The contributions of the anonymous Arctic reviewers are gratefully acknowledged.

\section{REFERENCES}

BARBER, D.G., DUNLOP, J.D., PIWOWAR, J.M., and LEDREW, E.F. 1989a. Image analysis on a Macintosh II. Proceeding of IGARSS '89 and the 12th Canadian Symposium on Remote Sensing, Vancouver, B.C. 1:150-153.

BARBER, D.G., RICHARD, P.R., HOCHHEIM, K.P. 1989b. Thermal remote sensing for walrus population assessment in the Canadian Arctic. Proceedings of IGARSS ' 89 and the 12th Canadian Symposium on Remote Sensing, Vancouver, Canada 4:2443-2446.

BURKHALTER, R., and KIENTZ, B. 1984. Counting big game by aerial thermography in the Arc-en-Barrois Forest. 18th International Symposium on Remote Sensing of Environment, Paris, France, 1-5 October 1984.

ESTES, J.A., and GILBERT, J.R. 1978. Evaluation of an aerial survey of pacific walruses (Odobenus rosmarus divergens). Journal of the Fisheries Research Board of Canada 35:1130-1140.

LAVIGNE, D.M., INNES, S., KALPAKIS, K., and RONALD, K. 1975. Harp seal aerial censusing. Unpubl. ms. Available at the Department of Zoology, College of Biological Science, University of Guelph, Guelph, Ontario, Canada. 94 p. 
MOEN, A.N., and JACOBSEN, F.L. 1974. Changes in radiant temperature of animal surfaces with wind and radiation. Journal of Wildlife Management 38(2):366-368.

RAY, G.C., and FAY, F.H. 1968. Influence of climate on the distribution of walruses, Odobenus rosmarus (Linnaeus). II. Evidence from physiological characteristics. Zoologica 53(1):29.

RAY, G.C., and WARTZOK, D. 1976. Analysis of marine mammal remote sensing data. The John Hopkins University, Baltimore, Maryland, U.S.A. Contract No. 03-6-022-35135. 14 p. Unpubl. ms. Available from Dr. G. Carleton Ray, University of Virginia, Department of Environmental Science, Charlottesville, Virgina 22904, U.S.A.

1980. Remote sensing of marine mammals of Beringeo. Results of BESMEX: The Bering Sea Marine Mammal Experiment. Contract report to the National Aeronautics and Space Administration NASA-9300. 77 p. Available from Dr. G. Carleton Ray, University of Virginia, Department of Environmental Science, Charlottesville, Virgina 22904, U.S.A.
RICHARD, P.R., and CAMPBELL, R.R. 1988. Status of the Atlantic walrus, Odobenus rosmarus rosmarus, in Canada. Canadian Field Naturalist 102:337-350.

RICHARDS, J.A. 1986. Remote sensing digital image analysis: An introduction. Berlin: Springer-Verlag. 281 p.

WARTZOK, D., and RAY, G.C. 1975. A comparison of the accuracy and precision of visual and photographic aerial censuses of ice-inhabiting marine mammals: Results of a simulated flight. Workshop on Remote Sensing of Wildlife, 17-20 November 1975, Quebec, Canada. 167-187.

WILKINSON, L. 1987. SYSTAT: The System for Statistics. Unpubl. ms. Available at SYSTAT, Inc., 2902 Central Street, Evanston, Illinois 60201, U.S.A.

YAREMCHUK, G., and BARBER, D.G. 1985. An aerial remote sensing system for arctic marine mammal research. Remote Sensing in Manitoba (Department of Natural Resources, Winnipeg, Manitoba) Oct. 1985:10-13. 